Brit. J. industr. Med., 1956, 13, 260

\title{
CARCINOMA OF THE LUNG IN WORKMEN IN THE BICHROMATES-PRODUCING INDUSTRY IN GREAT BRITAIN *
}

\author{
BY \\ P. LESLEY BIDSTRUP and R. A. M. CASE
}

From the Department for Research in Industrial Medicine (Medical Research Council), the London Hospital, and the Chester Beatty Research Institute, the Institute of Cancer Research, the Royal Marsden Hospital, London

(RECEIVED FOR PUBLICATION FEBRUARY 17, 1956)

The chromates-producing industry provides the basic chromates, sodium and potassium dichromate or monochromate, from which metallic chromium and the chromium compounds used in industry are obtained. The process involves extraction of chromium from the ferrous ore known as chromite or chrome ironstone, $\mathrm{FeO} . \mathrm{Cr}_{2} \mathrm{O}_{3}$ which contains 40 to $50 \%$ chromium and small amounts of alumina and silica. The ore is dried, crushed, mixed with limestone and the carbonate either of sodium or potassium and heated in a rotary furnace to convert the insoluble oxide to soluble monochromate. The monochromate is extracted from the furnace roast by repeated washing with water and treated with sulphuric acid to form dichromate, with sodium sulphate as a by-product.

Carcinoma of the lung in employees in the chromates-producing industry has been investigated and recognized as an occupational hazard in Germany (Pfeil, 1935; Alwens, Bauke, and Jonas, 1936; Teleky, 1936; Gross and Kölsch, 1943) and more recently in the United States of America (Machle and Gregorius, 1948; Baetjer, 1950a, b; Mancuso and Hueper, 1951; Gafafer, 1952). An investigation has been in progress in the industry in Great Britain since 1948 and the results are reported in this paper.

One of us has previously published the results of a clinical and radiographic investigation of men employed in the chromates-producing industry in Great Britain (Bidstrup, 1951). Seven hundred and twenty-four workmen were interviewed and radiographed and among these one was found to have carcinoma of the lung, from which he died during the survey. It was obviously not possible to

*The term " chromates-producing industry" is used throughout this paper to refer to the manufacture of bichromates from chromite ore, and not to any of the industries in which chromium and its compounds are used. decide whether this indicated a true increase of the incidence of carcinoma of the lung amongst these men, and an attempt has been made to follow the mortality experience of the remaining 723 persons from the time that the original survey finished on November 1, 1949, until August 31, 1955, a period of five years and 10 months.

The one case discovered in the course of the survey was found as a direct result of the investigations made at that time and is therefore disregarded in the statistical studies that follow, since it is obvious that the examinations made would tend to discover cases that might not otherwise have been correctly diagnosed. From the completion of the survey in 1949 until the further radiographic survey undertaken in 1955, the diagnosis of lung cancer as the cause of death in any individual case would have been made in a way not affected by a tendency to be looking for such a cause of death. In all cases the diagnosis was made either by the patient's usual medical attendant or in a hospital, but not by a works physician advised to keep an especial watch for such a condition. The doctors making the diagnosis would have no special knowledge of the previous survey and of the suspected risk so that there is no reason to believe that the results to be reported are affected by a diagnostic bias resulting from the investigation.

\section{Method of Follow-up Study}

The three factories at which the original survey was made are situated in different places in Great Britain. One is in a conurbation in England and Wales, one in a similarly constituted area in Scotland, and one in an urban area with a population between 50,000 and 100,000 in England and Wales. Because of geographical and other difficulties it was not possible to observe and record by personal interview the fate of each of the 723 workmen alive when the 
survey ended in 1949 . The method adopted was to supply the management at each works with a set of cards giving the name, address, and survey number of each man. When a man left the works for any reason his card was returned stating the date on which he left and the reason given for leaving. The fact that the reason for leaving is not known in only four cases is a measure of the effectiveness of the system, and of the cooperation of the management. These four cases have been included among those who have sought other employment since enquiries have failed to establish that they have died.

\section{Results}

Three hundred and thirty-three of the 723 men still alive when the 1949 survey ended are no longer employed in the chromates-producing industry. Table 1 shows the reasons given for leaving. Two

TABLE 1

REASONS GIVEN FOR LEAVING EMPLOYMENT IN CHROMATES-PRODUCING INDUSTRY

\begin{tabular}{c|c|c|c|c|c|c}
\hline Factory & $\begin{array}{c}\text { No. of } \\
\text { Employees } \\
\text { (1949) }\end{array}$ & \multicolumn{2}{|c|}{ Retired } & \multicolumn{1}{|c|}{$\begin{array}{c}\text { Sought } \\
\text { Other } \\
\text { Employment }\end{array}$} & Died & Total \\
\hline I & 179 & 1 & 4 & 79 & 9 & 93 \\
II & 500 & 4 & 45 & 130 & 48 & 227 \\
III & 44 & 1 & 2 & 8 & 2 & 13 \\
\hline Total & 723 & 6 & 51 & 217 & 59 & 333 \\
\hline
\end{tabular}

hundred and seventeen of these left at different times during the period 1949 to 1955 to seek other employment, and it has not been possible to discover what has happened to them. In the case of the 57 men who have retired because of age or ill-health, it has been possible to ascertain that they are still living and that none of them has symptoms suggestive of carcinoma of the lung.

Fifty-nine men are known to have died and the assigned cause of death was carcinoma of the lung in 12 cases (Table 2). The diagnosis was confirmed

TABLE 2

DEATHS BETWEEN NOVEMBER 1, 1949, AND AUGUST 31, 1955, IN 723 CHROMATES WORKERS EXAMINED IN 1949

\begin{tabular}{c|c|c|c|c}
\hline Factory & $\begin{array}{c}\text { Ascribed to } \\
\text { Carcinoma } \\
\text { of Lung }\end{array}$ & $\begin{array}{c}\text { Ascribed to } \\
\text { Neoplasms at } \\
\text { Other Sites }\end{array}$ & $\begin{array}{c}\text { Ascribed to } \\
\text { Other Causes }\end{array}$ & Total \\
\hline I & 3 & 3 & 3 & 9 \\
II & $9^{*}$ & 6 & 33 & 48 \\
\hline III & + & - & 38 & 59 \\
\hline Total & 12 & 9 & 2 & 2 \\
\hline
\end{tabular}

*One man from factory II who did not take part in the survey is known to have died from lung cancer.

tThe diagnosis of lung cancer has been made in two other men who are still alive, one of whom took part in the survey.

by necropsy in four cases, and by histological examination of bronchoscopy specimens in three others. There seems to be no reason to doubt the diagnosis made on clinical and radiographic findings in the other five cases.

In nine cases death was ascribed to neoplasms at sites other than the lung and in the remaining 38 cases to other causes.

Three hundred and ninety of the original 723 men are still employed in the industry, and of these 367 have been radiographed again during 1955 . One man aged 51 was found to have carcinoma of the lung, but was still alive at the end of August, 1955. Even had he been dead, the case could not have been used in the statistical analysis since the further radiography would have caused a bias in recognizing the condition.

\section{Method and Results of Statistical Analysis}

The method of analysis adopted has been based on the comparative composite cohort analysis technique described in detail by Case and Lea (1955) using analytical tables prepared for this purpose by Case and Pearson (1955). The tables selected were based on the years 1951, 1952, and 1953 , the median years of the period of survey, and were compiled from statistics relating to the male population of England and Wales. An investigation had verified that the secular changes in all the agespecific death rates used were sufficiently near to being linear over the period of the survey, and the midpoint of 1951-53 sufficiently near to the midpoint of the period of the survey, to ensure that no appreciable error would be introduced by using these tables. Since one of the factories concerned was in Scotland, a special calculation was made from data published by the World Health Organization (1955) relating to age-specific death rates by sex for cancer of the respiratory system in England and Wales and in Scotland. This calculation verified that the use of tables based on England and Wales would not materially affect the calculations.

The method of analysis requires a statement of the number of years of life experienced by the 723 men in each of a series of age groups, grouped in five-year intervals, over the whole period of the survey. From this statement, the "expected" number of deaths from a particular cause can readily be calculated from the age-specific death rates from that cause given in the analytical tables. ("Expected" is used in this sense throughout this paper to mean the number of deaths from the particular cause being discussed that would have occurred had the mortality from that cause which affects the general male population of England and Wales acted with the same severity on the series of men being studied, due allowance being made for the age of the men and secular variations in the mortality rates.) Three categories of causes of death have been considered, 
namely, deaths from carcinoma of the lung, deaths from neoplasms at other sites, and deaths from other causes. In all cases the entry on the death certificate which was used in our calculations was the cause of death to which the Registrars-General had assigned the death for the purpose of computing their returns.

The calculation of the statement of life experience in each age group is rendered more complicated than the similar calculation shown by Case and Lea (1955) because 217 men disappeared from observation by leaving their employment during the survey, but since we know both their age and the date at which each one left it has been possible to include the time that elapsed before they did leave in the statement. The results of the statistical analysis are shown in Table 3, and the figures are broken down to show the age distribution of the

TABLE 3

THE NUMBER AND AGE DISTRIBUTION OF DEATHS EXPECTED AND FOUND

\begin{tabular}{|c|c|c|c|c|c|c|}
\hline & Age & $<45$ & $45-$ & $55-$ & $65+$ & $\begin{array}{c}\text { All } \\
\text { Ages }\end{array}$ \\
\hline $\begin{array}{l}\text { Carcinoma } \\
\text { of Lung }\end{array}$ & $\begin{array}{l}\text { Expected } \\
\text { Found } \\
\mathbf{P} \text { for in- } \\
\text { crease found }\end{array}$ & \multicolumn{2}{|c|}{$1 \cdot 3$} & \multicolumn{2}{|c|}{$2 \cdot 0$} & $\begin{array}{l}12^{3.3} \\
0.005\end{array}$ \\
\hline $\begin{array}{l}\text { Neoplasms at } \\
\text { other Sites }\end{array}$ & $\begin{array}{l}\text { Expected } \\
\text { Found } \\
\text { P for dif- } \\
\text { ference }\end{array}$ & \multicolumn{2}{|c|}{$\begin{array}{l}5 \cdot 6 \\
6\end{array}$} & \multicolumn{2}{|c|}{$\begin{array}{l}2 \cdot 3 \\
3\end{array}$} & $\begin{array}{l}7.9 \\
9 \\
0 \cdot 7\end{array}$ \\
\hline $\begin{array}{l}\text { Other } \\
\text { Causes }\end{array}$ & $\begin{array}{l}\text { Expected } \\
\text { Found } \\
\text { P for dif- } \\
\text { ference }\end{array}$ & $\begin{array}{l}4 \cdot 2 \\
3\end{array}$ & $\begin{array}{l}5.9 \\
8\end{array}$ & $\begin{array}{l}12 \cdot 4 \\
12\end{array}$ & $\begin{array}{l}13 \cdot 8 \\
13\end{array}$ & \begin{tabular}{|c|}
$36 \cdot 3$ \\
38 \\
$0 \cdot 8$
\end{tabular} \\
\hline
\end{tabular}

deaths found and expected in each of the three categories examined.

\section{Discussion}

The figures for deaths from neoplasms at other sites than the lung and for deaths from other causes can be dismissed very briefly since it is obvious that they do not show any statistically significant difference between the numbers found and expected for these causes of death nor does the age-distribution differ. We must therefore conclude that workers in the chromates-producing industry are not shown to suffer an excessive or to enjoy a diminished mortality from neoplasms other than carcinoma of the lung or from other causes of death.

When we come to consider the mortality from carcinoma of the lung, the figures show a statistically significant increase of deaths found over deaths expected from this cause (P=0.005 for the increase) and an excessive mortality from carcinoma of the lung must therefore be admitted. The figures for the distribution of the deaths also show a tendency for deaths to be occurring disproportionately early, and although the scanty amount of data available here does not allow us to claim that the figures are statistically significant, the trend is discussed because such an alteration in mortality pattern would be expected if an environmental cause of death with a fairly well defined latent period of around 15 to 25 years were to be superimposed on the pre-existing mortality pattern of a community like that described here ( $c f$. , Case, Hosker, McDonald, and Pearson, 1954).

The ratio between the mortality found from carcinoma of the lung in this sample of workers in the chromates-producing industry and that expected is $360 \%$, and it remains to consider whether any factors not connected with occupation might be operating amongst these men which could lead to a difference of this magnitude. The main differentials of this sort that have been established as affecting the incidence of carcinoma of the lung in large communities are sex, which is irrelevant to these studies, place of residence, social class, and smoking habits.

Place of Residence.-The population in the three factories is about evenly distributed between dwellers in a conurbation and dwellers in an urban area with a population in the range 50,000 to 100,000 persons. The fact that part of the conurbation population is resident in Scotland has already been shown to be immaterial. The RegistrarGeneral (1954) gives the age-specific death rates for carcinoma of the lung in 1951 for the various population density aggregates for England and Wales, and reference to these figures will show that whilst the rates for the conurbations are about $10 \%$ above the mean rate for males in England and Wales, the rates for the urban areas with populations in the range of 50,000 to 100,000 are almost that amount below the mean rate. The contribution to the findings due to place of residence must therefore be considered as trivial.

Social Class.-The chromates workers taking part in this investigation are mainly in social classes IV and V. Logan (1954) has studied the social class differences in mortality from carcinoma of the lung revealed by the 1951 census, and shows that, whilst there is now a suggestion of a social class gradient which was not apparent in 1921 or 1931, the standardized mortality ratios for social classes III, IV, and V are respectively $108 \%, 89 \%$, and $116 \%$ of the rate for the general population of males aged 20-64. We must therefore conclude that the differences due to social class could not contribute materially to the differences that we have found. 
Smoking Habits. - It might be suggested that the workmen in the chromates-producing industry include many heavy smokers, and that the deaths from lung cancer occurred entirely amongst these men. The general population includes a certain proportion of heavy smokers, and it would be necessary to postulate that the proportion of heavy smokers in the group under investigation was so much greater than in the general population that an increase of $360 \%$ of the mean rate would result. Stocks and Campbell (1955) give figures that probably reflect the smoking habits of the general population with a fair degree of accuracy, and their sample suggests that for urban areas, which would include conurbations, the percentage distribution of smoking habits for men aged 45-64 is non-smokers $3.9 \%$, pipe-smokers $7.1 \%$, cigarette-smokers-light $17.6 \%$, moderate $61.5 \%$, and heavy $10.5 \%$. Doll and Bradford Hill (1954) show that the incidence in their heaviest group of smokers defined as those who smoke more than 25 cigarettes a day, and roughly comparable with the definition of " heavy smoking" adopted by Stocks and Campbell, was just less than double $(200 \%)$ that of the mean rate for the general population, whilst the rate in the group corresponding to Stocks and Campbell's moderate smokers was about the same as the mean rate for the general population. Thus even if the smoking habits of the chromates workers were so changed from those of the general population that all of them fell into the category of heavy smokers, the increase of carcinoma of the lung that would then be expected would not satisfactorily account for the increase which we have observed. In fact, we have no reason to believe that their smoking habits are different from those of the general population, and an explanation based on a hypothesis of altered smoking habits would need to be supported by satisfactory evidence of such alteration before it could be seriously considered.

It would therefore seem that, in our present state of knowledge, the increased mortality from carcinoma of the lung which we have found amongst these workmen in the chromates-producing industry must be attributed to some factor associated with their occupational environment, and could not be explained by variations of mortality due to place of residence, social class, or smoking habits. We have expressed the opinion earlier that a diagnostic bias can also be excluded as a factor.

The survey was not designed to determine, and was inherently incapable of determining, the nature of the carcinogenic occupational factor.
The Latent Period.-Since only 12 deaths from carcinoma of the lung are considered in this series the number is too few to allow of an accurate calculation of the mean latent period after first exposure to risk. From the grouped data given in Table 4 the mean latent period is calculated to be 21 years with a standard deviation of 10 years and a standard error of the mean of three years. This

TABLE 4

ANALYSIS OF DEATHS ASCRIBED TO CARCINOMA

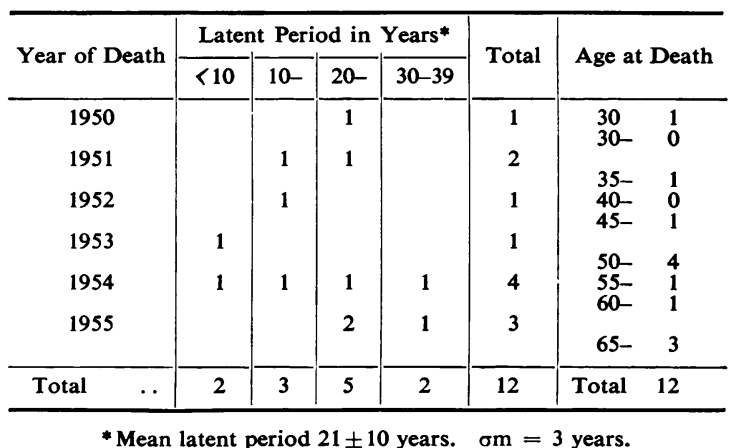

suggests that the latent periods which might occur in cases of carcinoma of the lung amongst workers in the chromates-producing industry will not differ greatly from those found for other types of cancer of occupational origin such as cancer of the bladder in the dyestuff-intermediates industry, for which the latent period is 18 years with a standard deviation of seven years (Case and others, 1954).

Where there is a long latent period of this kind calculations purporting to show the ratio between the risk in a given industry and the risk in the general population are relatively meaningless unless a sufficient number of cases have been studied in a sufficiently large population at risk to allow the calculations to be made of the final incidence of the particular cause of death in a cohort followed to extinction, and the figure so obtained to be compared with a similar final incidence figure for the general population ( $c f$. ., Case and others, 1954). Thus the statement that an increase of $360 \%$ of the mean rate has so far been found is not a final statement that the risk in the chromates-producing industry is only $360 \%$ of the mean, for by the time all the men at risk have lived their life span it will probably be found that the factor is very much higher.

There is therefore no point in trying to relate the quantitative results of this survey to the statement of Machle and Gregorius (1948) that the crude death rate amongst their workers in the chromates- 
producing industry in the United States of America was 25 times the normal. The results do, however, confirm from British data the conclusions of these authors and of other American authors (Baetjer, 1950a, b; Mancuso and Hueper, 1951; Gafafer, 1952) and also the conclusions of the German authors (Pfeil, 1935; Alwens and others, 1936; Teleky, 1936; Gross and Kölsch, 1943) that carcinoma of the lung is an occupational hazard of the chromates-producing industry.

\section{Summary}

A follow-up over about six years of the mortality experience of workers in the chromates-producing industry at three factories in Great Britain shows a statistically significant increase in the mortality from carcinoma of the lung. Twelve deaths were recorded in the series used for statistical analysis and only 3.3 expected. In addition to these 12 patients, three more, one of whom is dead and two still alive, were reported from the same factories.

This increased mortality is in accord with the findings of various authors (previously quoted) who have studied hazards to health in the chromatesproducing industry in Germany and in the United States of America.

The possibility that the increase found by us could be due to a non-occupational cause such as diagnostic bias, place of residence, social class, or smoking habits has been examined, discussed, and discarded, and we therefore conclude that carcinoma of the lung must be considered as an occupational hazard in the chromates-producing industry in Great Britain. The data that we have examined do not allow us to form any opinion about the nature of the carcinogenic occupational factor.

The mortality experience of the chromates workers taking part in this investigation from neoplasms at other sites and from deaths from other causes does not seem to be altered from the mortality expected in a comparable section of the general population of England and Wales.

We acknowledge the cooperation of the companies concerned throughout these investigations and particularly in making available to us the information about the employees who took part in the 1949 survey on which the follow-up study and conclusions reported here are based. It would not have been possible to make the investigation without the assistance which the firms have given at every stage of our enquiries. We acknowledge also the cooperation of many doctors who have sent us copies of case-records and necropsy reports.

We are grateful to Dr. Donald Hunter, Director of the Department for Research in Industrial Medicine, Medical Research Council, London Hospital, for advice and criticism.

In so far as one author is a member of the staff of the Chester Beatty Research Institute, this investigation received support from grants to this Institute from the British Empire Cancer Campaign, the Jane Coffin Childs Memorial Fund, and the Anna Fuller Fund.

\section{REFERENCES}

Alwens, W., Bauke, E. E., and Jonas, W. (1936). Arch. Gewerbepath., Gewerbehyg., 7, 69 .

Baetjer, A. M. (1950a). Arch. industr. Hyg., 2, 487.

, (1950b). Ibid., 2, 505.

Bidstrup, P. L. (195i). British Journal of Industrial Medicine, 8, 302. Case, R. A. M., and Lea, A. J. (1955). Brit. J. prev. soc. Med.,

and Pearson, J. T. (1955). Methods and Tables for Comparative Composite Cohort Analysis. (1) Tables. Neoplastic Diseases. London. Institute of Cancer Research. Royal Cancer Hospital. (Unpublished Institute Record.)

Hosker, M. E., McDonald, D. B., and Pearson, J. T. (1954). British Journal of Industrial Medicine, 11, 75 .

British Journal of Industrial Medicine, 11, 75.
Doll, R., and Hill, A. B. (1954). Brit. med. J., 1, 1451.

Doll, R., and Hill, A. B. (1954). Brit. med. J., 1, 1451.
Gafafer,W. M. (1952). Publication 192. Federal Security Agency, W. M. (1952). Publication 192.
Washington. Uederal

Gross, E., and Kölsch, F. (1943). Arch. Gewerbepath. Gewerbehyg. 12, 164 .

Logan, W. P. D. (1954). Brit. J. prev. soc. Med., 8, 128.

Machle, W., and Gregorious, F. (1948). U.S. Publ. Hlth Rep., 63, 1114 .

Mancuso, T. F., and Hueper, W. C. (1951). Industr. Med. Surg., 20, 358.

Pfeil, E. (1935). Dtsch. med. Wschr., 61, 1197.

Registrar-General (1954). Statistical Review of England and Wales for 1951. Text volume p. 198. H.M.S.O., London.
H. M . The

Stocks, P., and Campbell, J. M. (1955). Brit. Med. J., 2, 923.

Stocks, P., and Campbell, J. M. (1955). Brit. Med.
Teleky, L. (1936). Dtsch. med. Wschr., 62, 1353 .

Teleky, L. (1936). Dtsch. med. Wschr., 62, 1353 .
World Health Organisation (1955). Statist. Rep., 8, 265 . 